\title{
Conservative, Liberal, Radical: Three Ways of Understanding Gay Issues in Church and Society
}

\section{J. Clark Saunders}

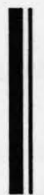

After serving as minister at Knox-Metropolitan United Church in

Edmonton for eleven years, J. Clark Saunders (jclarks@gatewest.net) is now at Westworth United Church in Winnipeg. He chaired the first Diversity Conference in Edmonton in 1998 on the theme "Embracing Spirituality/Embracing Sexuality."

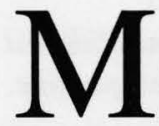
uch has been said and written about "the Issue," as it came to be called in 1988, in the United Church of Canada - the issue being whether or not to ordain and commission "selfdeclared practicing homosexuals" to ministry in Canada's largest Protestant denomination. The issue polarized the United Church in a way that was perhaps unprecedented in the church's experience. Various attempts have been made to understand the reasons for the deep divisions and to analyze their origins. One approach has understood the 'conservatives' on the issue as being concerned primarily with morality, while the 'liberals' saw the issue primarily in terms of justice. Conservatives were reluctant to agree to ordination and commissioning because they were unsure of what range of moral behaviors they were being asked to affirm. Would they be condoning a minister living with a same-sex partner in the manse, for example? Would they be saying yes to promiscuity? Some even wondered whether they would be opening the door to pedophilia. The liberals, on the other hand, pointed out that the church had never before explicitly excluded any group of people from consideration for ordered ministry and that to do so now would be patently unjust. Issues of justice would have to be settled first; discussions about personal morality might come later. In addition to the conservative and liberal perspectives, there was a more radical stance adopted by

torquere: Journal of the Canadian Lesbian and Gay Studies Association / Revue de la Société canadienne des études lesbiennes et gaies

Vol. 2 (2000) @ CLGSA/ SCELG 
some gay and lesbian people and their supporters, but which was not discussed very widely. The characteristics of a radical approach to gay issues - together with a development of conservative and liberal understandings - are explored in this paper.

A few words of caution are in order at the outset. First, it needs to be said that my ideas have been influenced primarily by the writings of gay ethicists, by conversations with gay men, and by my own experience. It seems likely that much that follows will resonate with lesbian readers - and, in fact, lesbians have often affirmed these ideas in discussion at workshops - but direct reflection on lesbian experience is largely absent. I would welcome further lesbian contributions to the discussion.

Second, while the three basic approaches which I identify (conservative, liberal, and radical) may be found in society at large, I am concentrating on expressions of these views as found in Christian circles. This means, for example, that biblical and theological references are included. But many of the social attitudes that are found in the church can be found elsewhere as well.

Finally, although readers (of whatever sexual orientation) may find themselves identifying consistently with one of the three approaches, it may be that they will move back and forth from one to another, depending on the topic, and may even locate themselves somewhere between two positions. Some may find their position changing and evolving over time. When I first started to think about these issues I would probably have located myself uneasily between a liberal and a radical stance. As time goes by, I find myself shifting perceptibly toward a radical position.

Although I have tried to be both critical and respectful of a range of points of view, elements of caricature may have crept into the way a purely liberal or essentially conservative or stereotypically radical viewpoint is expressed. I hope not. In any case, my aim is to outline a range of mindsets with sufficient clarity that their consistency with themselves and their distinctiveness from one another may be apparent.

\section{Scripture}

Christians often like to begin with the Bible. Certainly, when it comes to gay issues, some Christians who rarely cite chapter and verse onother subjects can be seen using scripture as a weapon against the 


\section{$60 /$ Saunders}

enemy. In any case, approaches to scripture provide a useful initial illustration of the ways proponents of the three respective positions see things.

The Christians whom I would describe as conservative tend to take a fairly - although, their archcritics would say, a selectively literal approach to scripture. They range from those who subscribe to the idea of the verbal inerrancy of scripture to those who, while understanding the Bible as divinely inspired, have a somewhat looser understanding of this. Conservatives will be found in larger proportions in such evangelical denominations as Baptist, Alliance, and Pentecostal churches. They will be found in smaller proportions in mainline denominations like the United Church, although in 1988 their ranks were swelled by people who might not have been as familiar with the Bible as those who are consistently conservative on a range of issues, but who found that a more literal approach to the texts about homosexuality tended to support their attitudes.

For purposes of comparison, we may isolate perhaps the clearest Hebrew scripture or Old Testament text on the subject of homosexuality: Leviticus 20:13 ("If a man lies with a male as with a woman, both of them have committed an abomination; they shall be put to death; their blood is upon them"). ${ }^{1}$ This passage, like nearly all biblical references to homosexuality, singles out male homosexuality. ${ }^{2}$ To a similar prohibition in Leviticus 18:22, this text adds the death penalty. The selective literalism of most conservative Christians might make them shrink from invoking the death penalty for homosexual acts in contemporary society, but the text's use of the word "abomination" to describe homosexual behavior would still be seen as a clear sign of God's disapproval. Based on this understanding, gay men would be regarded as unsuitable leaders and role models in the church and would therefore be denied ordination. And same-sex couples would be denied the church's blessing in the form of a holy

'The Scripture quotations contained herein are from the New Revised Standard Version Bible, copyright 1989 by the Division of Christian Education of the National Council of Christ in the U.S.A. Used by permission. All rights reserved.

${ }^{2}$ Limitations of space prevent a detailed exploration of the reasons for this, although it might be useful to begin with the fact that Israel was a patriarchal society in which homosexual behavior did not advance the allied social concerns of procreation and the passing on of property. 
union or covenanting service.

A liberal approach to the same text would emphasize issues of context. Following the historical-critical method, liberals would point out that the levitical prohibition is part of a holiness or purity code, ${ }^{3}$ many aspects of which are not taken literally by Christians today the eating of pork, for example, or the wearing of cloth made of two kinds of fabric. They would explore the meaning of "abomination" and claim that it is a term that is used in the Bible to describe any practice that is characteristic of an alien culture or religion (Millward 12). ${ }^{4}$ Hebrews, for example, are an abomination to Egyptians because they are shepherds (Gen. 46:34). Further, liberals who abhor the death penalty for any crime or practice might argue that its invocation in Leviticus 20:13 calls the applicability of the entire verse into question.

Stepping back further from the specific text, liberals might point out that, in the whole range of scripture, homosexuality takes up only a minuscule amount of space, that it is often dealt with in the context of a particular concern (temple prostitution, for example, or - in the case of Sodom and Gomorrah - homosexual and heterosexual rape and the obligations of hospitality), and that there is no record of Jesus himself ever having spoken about it. To these considerations liberals might add that, while homosexual acts might have been known in ancient Israel, our ancestors in the faith did not have the benefit of modern sciences and social sciences and therefore did not have a clear understanding of homosexuality as such. All of which, in the liberal view, makes scripture an unreliable guide and an unhelpful source when it comes to making judgments about homosexuality today. When it comes to issues like ordination and same-sex unions, liberals are guided more by their sense of Christian love and justice and by their own common sense than by scriptural texts.

A radical approach to Leviticus 20:13 differs from a liberal position in that it refrains from providing cultural excuses for such an injunction. American theologian and United Church of Christ minister Gary David Comstock argues that the very existence of such a verse suggests that homosexuality must have been perceived

${ }^{3}$ For three contrasting analyses of the impulses underlying Israel's purity laws see Comstock (85-68), Countryman (61-64), and Helminiak (43-54).

${ }^{4} \mathrm{See}$ also Helminiak who explores the sense in which "abominable" means "unclean" (48). 
as a threat to patriarchy (39). To those liberals who say that the Bible prescribes stoning for gays only once in all its pages, Comstock asks, "How many times and in how many ways do we have to be told that we should be killed before we take it seriously? Is not once enough?" (39).

Just as some radical feminist writers see the Bible as a patriarchal document which deserves to be discarded or, at the very least, approached with what Elizabeth Scheussler Fiorenza ${ }^{5}$ describes as a "hermeneutic of suspicion" $(15,19-20)$, some radical gay thinkers see the Bible - to the extent that it deals with homosexuality at all as a homophobic document which deserves similar treatment. Some radical feminist scholars read the Bible as literature that needs to be searched for subversive texts or signs of suppressed or marginalized writing and story-telling in an effort to recover elements of women's experience. Similarly, some radical gay thinkers search the Bible for remnants of suppressed stories of same-sex bonding (e.g., Naomi and Ruth, David and Jonathan, Jesus and the beloved disciple).

The difference in the ways that liberals and radicals read the Bible shows up as well in the way in which they understand Jesus' relationship to the hermeneutical task. Liberals are inclined to try to discern the mind of Christ, asking what Jesus would say or do 'if he were alive today'. Radicals like Comstock point out that Jesus has been co-opted by a multiplicity of groups - liberals included - to endorse their theology and their programs and is not free from our tendency to project our interests onto him (93). While Canadian Lutheran Ralph Wushke sees the positive in this and encourages us to search for a "queer Jesus" who will speak to queer experience, ${ }^{6}$ Comstock himself suggests that we "leave Jesus" and imagines Jesus saying, "Don't look to me for answers; you're on your own ... Look to each other; don't look to me" (99).

\section{Christian Anthropology}

Moving a step beyond the Bible, the three viewpoints can be found to differ when it comes to theology - and particularly when it comes to their understanding of human nature and of God's intention for humanity.

${ }^{5}$ Goss $(87-111)$ is one who acknowledges his debt to Scheussler Fiorenza.

${ }^{6} \mathrm{Goss}$ provides an exploration of the idea of a queer Christ and a queer Christology (77-85). 
Conservative Christians tend to understand humans to have been created as heterosexual beings. ${ }^{7}$ Their view is heterosexist in the sense that heterosexuality is understood as the proper standard against which other sexual orientations are measured. According to this standard all other orientations must be considered perversions.

On this reading, homosexuality is seen as being 'unnatural' contrary to what nature (and God) intended. As a departure from nature, homosexual practice and homosexuality itself are seen as sinful - a rejection of God's plan and intention. While some might see the element of sin as willful on the part of the homosexual (in which case repentance is the appropriate response), others tend to look on homosexuality as a sickness or disorder from which the individual should be delivered by means of a cure. Both variations of the sin/sickness model inform the 'ex-gay' movement ${ }^{8}$ by which persons are encouraged to reject their homosexuality in favor of heterosexuality - or at the very least are counseled not to act on their homosexual impulses. ${ }^{9}$ Gay men who themselves espouse a conservative Christian anthropology are more likely than liberals or radicals to heed this counsel.

Liberals, on the other hand, understand humanity to be sexually diverse. They base their sense of what is 'natural' on what is found in nature and point to animal species which exhibit signs of bisexuality and homosexuality. ${ }^{10}$

For liberals, human diversity - racial, ethnic, sexual, etc. - is often cited as a value. However, as we will see later, heterosexism may still

${ }^{7}$ Drawing on a typically conservative reading of the second creation story in Genesis they are fond of pointing out that God made Adam and Eve, not Adam and Steve.

${ }^{8}$ Faris, a conservative United Church minister, supports the value and validity of a 'cure' (103-16), although the studies which he quotes in support of his argument have been judged unreliable by liberals and radicals.

'In some denominations - the Anglican Church, for example - a clergyperson's sexual orientation is not in itself at issue. However, ordained persons of whatever orientation are expected to practice chastity unless they are married. (See Ferry for one gay clergyman's experience of this policy in the Anglican Church as well as for an outsider's view of developments in the United Church.) For conservatives, the oftquoted formula for ordained and unordained alike is, "Chastity in singleness; fidelity in marriage."

${ }^{10}$ It is interesting to note a conservative response to this perception about nature. I recall Anita Bryant once affirming that homosexuality was unnatural because it was not found in animal species. When it was pointed out to her that homosexuality had indeed been observed in nature, she shifted her ground - 180 degrees - and argued that humans should reject homosexuality on the grounds that to engage in it would level of animals. 
inform a subtle prejudice that continues to affirm a kind of hierarchy when it comes to the variety of sexual patterns of behavior. Though more subtle (or insidious, according to one's viewpoint) than the conservatives, liberals tend to see heterosexual social models as the best ones for all people - regardless of sexual orientation - to follow. Gay relationships that seem to follow a straight model tend to have their endorsement. Consequently, liberals may be found supporting the idea of blessing same-sex unions in church and advocating for same-sex partner benefits as a matter of social policy.

Whereas liberals, after scratching at the surface of their arguments, may be found to be merely tolerating diversity while clinging to a traditional hierarchy of value, radicals may be seen to celebrate that diversity. In fact, some radicals go beyond affirming the more-orless equal values of different sexualities and almost overstate the value of homosexuality and its contribution to humanity in general. At the very least, radicals are unapologetic about the idea that the sexual diversity found in nature and in human nature is a sign of God's good creation rather than a sign of the Fall (conservative) or even a morally neutral fact of life (liberal). And while conservatives might tolerate gay clergy who live a chaste life, and liberals might tolerate gay clergy who live in a stable, monogamous relationship with a partner, radicals would put no such conditions on the suitability of gay people for ordination.

It would probably be agreed by all three groups that, in terms of Christian anthropology, sin is failure to fulfill God's intention for us. Where would each of these groups locate sin in the case of the subject under discussion? As we have seen, conservatives identify sin with homosexuality itself. Radicals counter by accusing conservatives of the sin of homophobia - and gay conservatives of internalized homophobia. Two hallmarks of traditional liberalism are tolerance and a rather optimistic view of human nature. Theological liberals tend to downplay the significance of sin and call on both conservatives and radicals to adopt a more tolerant and less judgmental attitude toward each other.

\section{Body and Spirit}

A related theological concern has to do with the way the three groups view the relationship between body and spirit. The Judeo-Christian tradition is a checkered one and provides source material for a variety 
of approaches.

Conservatives tend to draw on those traditions (e.g., the Apostle Paul) that see a dichotomy between body and spirit. There is a great divorce between the two. Spirit is good; body is bad. Our true, essential selves, the selves we are to aspire to being, are spiritual. The body and its appetites represent a lower, physical plane of being that we are to overcome and subdue.

It is perhaps not surprising that this view of humanity has been put forward primarily by men. It represents an inner conflict that reflects the experience of many males. Some years ago a book appeared on the subject of women's bodies. It was called Our Bodies, Our Selves. When a volume for men in similar format came along, it was called Man's Body: An Owner's Manual (Nelson 106). The suggestion is that women, with their natural bodily rhythms, identify more closely with their bodies. Men may be more inclined than women to see their bodies as an element that often seems disobedient, out of control, and alien to their spiritual aspirations - something to rise above. Certainly, conservative Christians tend to be suspicious of the physical and to distrust the body's sexual instincts. They limit the legitimate expression of this powerful drive to one setting only: heterosexual marriage.

Liberal Christians tend to have a more ambiguous attitude toward our physical being. A report on human sexuality prepared in 1984 for the United Church of Canada (which many consider a largely liberal denomination) reflected this ambiguity in its title, Gift, Dilemma and Promise. Although the report upset conservatives by its questioning of rigid rules when it comes to sexual behavior, there is still the sense that our bodies present us with difficult problems.

There is, on the other hand, a tendency among radicals (e.g., J. Michael Clark, who follows the work of such writers as Beverly Harrison and James Nelson) to erase the boundary between body and spirit. Taking a more holistic approach (and drawing in some cases on Judaic tradition), some radicals speak of our "bodyselves" (Nelson 30-31) and claim that we are our bodies - or, at least, that we cannot be known apart from our bodies. The goal of morality for them is not that spirit should win in the battle against body, but that each bodyself should become an integrated whole. As part of this approach, bodies are to be affirmed, as is the pleasure they can experience - pleasure that, for both gays and straights, may not be 


\section{$66 /$ Saunders}

limited to the marriage bed. Rather than the traditional term "incarnation," radicals sometimes use the word "embodiment" to describe the physical presence of the divine in human life.

\section{Integration vs. Distinctiveness: Defining the Difference between Gay and Straight}

Linked to some of the theological and social assumptions which the three perspectives make is a range of opinion as to just how different gay people are from straight people. Are gays and straights essentially alike except for 'what they do in bed'? Or do the differences run deeper than that?

Conservatives tend to talk about 'the gay lifestyle' in a way that suggests, first, that there is only one way to be gay and, second, that being gay involves a whole package of social behaviors, attitudes and political ambitions. Gays tend to be anathematized - or even demonized - as degenerate, predatory, and promiscuous. Conservatives tend to speak of the 'gay agenda' which in their view involves securing not equal rights (as liberals might call them), but special rights. These would include the right to marry (or have their relationships legally recognized in some other way) and the right to adopt children. Conservative biblical and theological assumptions render such claims unacceptable. In conservative thinking, the differences between gay and straight are profound. Gays are seen as inherently morally inferior.

Liberals tend to emphasize the areas of similarity between gays and straights. The only essential difference, according to this view, is the sex to which one happens to be attracted. Gay aspirations (according to both gay and straight liberals) are seen to be largely the same as those of straight people: the satisfaction of long-term relationships, the carrying out of meaningful work, the opportunity to have families, the ability to make a contribution to mainstream society, etc.

However, some have seen an implied heterosexism in some expressions of liberal attitudes. The impression that is sometimes given is that gay people can be 'just as good as' straights. Straight standards, however, are tacitly - and sometimes explicitly - assumed to be the norm. As a liberal gay-positive pamphlet called What the Bible Says to Homosexuals puts it, "As the relationship between homosexuals becomes recognized as parallel to a heterosexual 
relationship, it becomes possible to apply to a homosexual union the discipline expected in a heterosexual marriage" (Millward 10). Minority experience, it seems, is still to be interpreted in the light of majority culture.

Radicals, on the other hand, tend to agree with conservatives that there is more to being gay than just how people have sex. Gayness is bound up with an entire culture. It involves a distinct sensibility and a distinct kind of socialization. " To obliterate the line between gay culture and heterosexual culture would mean a loss, not only to gays, but to straights as well. Mainstream society benefits from the contribution that a distinctively and discernibly gay presence can make to it. $^{12}$

In comparing liberal and radical attitudes, a parallel may be seen with viewpoints expressed about race in the era of the civil rights movement in the United States. Liberals were inclined to say that the only significant difference between blacks and whites - and the basis of prejudice - was the color of their skin. ${ }^{13}$ A more radical approach identified (and celebrated) many differences between black and white culture - and led to the establishment of departments of AfroAmerican Studies at universities all over the United States. In Canada, a comparable issue might be the historical debate about whether it is in the best interests of aboriginal peoples to be assimilated into the predominant culture or to remain a distinct social entity. When an emphasis on difference leads to discrimination, of course, the challenge is to preserve and celebrate what is life-giving about the

\footnotetext{
"Charles Kaiser refers to two well-known secular writers who dissent from this radical viewpoint and line up with the position I am describing as liberal. He writes, "Gore Vidal, a child of the fifties, has always insisted 'there are no homosexual or heterosexual persons, only acts ... I never in my life accepted that these two categories existed. And when they began on 'gay sensibility' back in the sixties and seventies, I said, 'Well, if you think there is such a thing, what does Roy Cohn have in common with Eleanor Roosevelt?' Other than they liked their own sex" (Kaiser 96).

Kaiser continues: "The novelist, essayist, and biographer Edmund White is similarly skeptical about the notion of gay sensibility. 'What we can discuss ... is the gay taste of a given period,' he wrote in States of Desire. 'A taste cultivated (even by some heterosexuals) or rejected (even by many homosexuals)."' (White 259)

${ }^{12}$ For a lively discussion of the pros and cons of the assimilation of gay culture into mainstream culture, see Harris.

${ }^{13}$ Even Martin Luther King, in his "I Have a Dream" speech in Washington, dreamed of a day when his own children would be judged, not by the color of their skin, but by the content of their character.
} 
differences without using them as a justification for imposed segregation or unequal treatment.

The contrast between liberal and radical approaches to 'difference' can be illustrated by their attitudes toward gay marriage. In a letter to the editor of the Edmonton Journal, writer and energy consultant James Kennedy upholds what I call a radical view and critiques what I call a liberal position. Kennedy, who self-identifies as gay, argues against marriage for gays. Gays and "straight liberals" are misguided, he says, when they understand equality to mean equal access to marriage. He questions whether equality must take the form of "suburbia universalis," and suggests that gay people need to guard against "the power of dominant cultures to assimilate." Gays need to reflect on their own experience and to develop their own social institutions rather than borrowing from a different culture. "Our fight for civil rights," he says, "should be about substantive equality, not about appropriating labels developed by other cultures for their own use." The flaw in the obsession of "middle-class liberals" with extending the marriage franchise is that their efforts will have the effect of assimilating "a distinct minority into the mainstream ... Distinct religions, attitudes, languages and patterns of thought vanish into the stultifying abyss of mainstream culture. What unique contribution we might have made as an accepted (yet independent) voice is lost, and in its place we are offered full participation in someone else's culture." The radical position - and its contrast with that of the liberals - could hardly be better put.

\section{The Element of Choice}

Essential to the moral positions adopted by the three perspectives are their assumptions about the role of choice in matters of sexual orientation. Obviously the question of whether sexual orientation is 'given' or chosen has a bearing on the degree and kind of moral responsibility which follows.

Whether or not conservatives see all sexual orientation as a matter of choice, most seem to believe that homosexuality (and its inevitable 'lifestyle') is chosen. Those who see room for repentance clearly believe that another choice can be made. Even those who adopt the sickness/healing model believe that individuals can choose to seek healing for their condition. Healing may take the route of response/ behavior modification in the form of aversion therapy. Or it may 
address a perceived deficiency in childhood bonding with one or both parents. Even so, homosexuals, regardless of the degree of choice involved in their orientation, are seen to bear moral responsibility for choosing to remain in their current state or choosing to pursue wholeness.

Liberals, on the other hand, understand sexual orientation to be a 'given.' Although its origins may still be a mystery (whether caused by genetics or conditioning), it is not a matter of choice. While some may try to value homosexuality equally with heterosexuality, others look at gays with compassion. ('They can't help being the way they are; after all, given the way they are persecuted, who would willingly choose to be gay?') In either case, moral responsibility takes on a different form than it does for conservatives. Gays may not choose their orientation, but they can still make behavioral choices, and the best choice is long-term, monogamous relationships analogous to the 'best' heterosexual relationships. ${ }^{14}$

Radicals debate among themselves the relative merits of 'essentialist' and 'social constructionist' models for understanding sexual orientation. ${ }^{15}$ Essentialists - who would appear to be in the minority - suggest that gayness is essentially the same from one society to another and from one era to another. Social constructionists emphasize the ways in which they see sexual orientation - or at least its expression - as being culturally conditioned.

Radicals at the essentialist end of the spectrum - those, in other words, who suggest that sexual orientation is not chosen - may be alarmed at the way in which some conservatives and liberals discuss the implications of a possible discovery of a gay gene or studies that suggest a link between the size of a man's hypothalamus and his sexual orientation. Liberals may rejoice in discoveries that seem to support their idea that sexual orientation is inherent rather than chosen. Yet their sense of compassion (and implied superiority) and an inclination to feel sorry for those who bear the burden of homosexuality might lead them to conclude that if homosexuality is

${ }^{14}$ This is the liberal position espoused by Bishop John S. Spong (who has often been called a theological radical) and expressed in an address to the Diversity Conferences of Alberta Society at Knox-Metropolitan United Church, Edmonton, Alberta, on May 3, 1999.

${ }^{15}$ For a discussion of social constructionism and its limitations, see Stein. 


\section{0 / Saunders}

congenital it may also be preventable, and steps should be taken to eliminate the gay component from humanity. Conservatives who might be open to the idea that sexual orientation is inherent if it could be used in a way that would advance their antihomosexual position might also - though for different reasons - advocate measures to prevent people from being born gay.

Those who see sexual orientation as a social construct argue for an element of choice in our sexual self-understanding. One person, for example, may self-define as straight or bisexual in his twenties, but as gay in his forties. Another may find over time and through experience that a same-sex relationship meets deeper needs than an opposite-sex relationship. Still another may be attracted now to a man, now to a woman, and yet eschew traditional labels of sexual orientation.

In his book The End of Gay, Bert Archer argues for a fluid understanding of sexual orientation - and for more room for the element of choice. Archer sees gayness as a social construct that had value in the second half of the twentieth century for defining an identifiable group that was in search of social and political recognition. However, he claims that it is time to move on to new understandings of sexuality. Not surprisingly, many men for whom being gay is an 'essential' part of their identity were outraged by Archer's proposition.

Although many social constructionists might not go as far as Archer, it is interesting to find that some radicals agree with conservatives in seeing an element of choice in sexual orientation at least as it is lived out. But what the conservatives call bad, radicals call good. And, unlike some liberals, most radicals argue for valuing all orientations equally. Liberals - at least those who say of gays that they cannot help it - still operate out of a heterosexist hierarchy. Heterosexuals do not have to justify the way they turned out, but homosexuality - along with other minority orientations - has to be justified or explained or excused.

\section{Ethics}

Attitudes toward gay lifestyles and ethical behavior parallel some of the subjects that have already been examined. For conservatives, for whom any sexual activity outside marriage is regarded as sinful, chastity is the only option for homosexuals who may be unable to change their orientation. For liberals, as we have discussed, a hierarchy 
of options tends to put relationships analogous to heterosexual marriage at the top of the heap. Relationships or arrangements that are not committed, long-term, or monogamous are judged - as are heterosexual relationships that lack these characteristics - as inferior.

We have also seen that radicals tend to question the assumption that heterosexual values should be applied to homosexual life. To begin with, some point out, heterosexual values may not be working even for heterosexuals. In practice, heterosexual marriage is often much less than it is supposed to be. It is said that fifty percent of North American heterosexual marriages are not permanent; many marriages are not characterized by sexual fidelity; "traditional families"16 can be scenes of power inequities, domestic violence, oppression of women, etc. Furthermore, some changes in the meaning of sex for heterosexuals have undermined some of the grounds for criticism of homosexual activity. For example, straight couples who decide not to have children but still engage in sex cannot pretend that sex is justified solely or primarily as the means of procreation. If sex means something else - commitment, for example, or caring, or sheer pleasure - for straight people, then what is sauce for the goose is sauce for the gander. Sex may mean any or all of these things to homosexuals as well.

Some radicals question the value of monogamy, saying that it may (or may not) be appropriate for straights but need not be applied to gays. Some gay men, for example, may rejoice in whatever truth they find in the stereotypes proclaimed in the old double dactyl: "Higgamus, hoggamus, / Woman's monogamous; / Hoggamus, higgamus, / Man is polygamous." Monogamy, they might say, is a heterosexual value which sets out to domesticate straight men and tame their polygamous impulses. But gay men without family commitments should not be constrained by the same value (Long 23, 40).

Other (less extreme) radicals may not reject the 'value' of fidelity but may reinterpret it as implying a different kind of faithfulness than literal monogamy might require. For example, J. Michael Clark

\footnotetext{
${ }^{16}$ With regard to the well-worn phrase "traditional family values," conservatives see homosexuals as a threat to these values, while liberals try to offer reassurances that homsexuals are not a threat. Radicals, on the other hand, agree that homosexuality does challenge traditional family values and claim that these values deserve to be challenged.
} 
takes a principle enunciated by Carter Heyward and builds on it. "We must be real with one another, really present," writes Heyward (131). Clark takes this principle as a foundation for a fidelity that is neither bound by monogamy nor restricted to the purely sexual aspects of a relationship. Clark understands fidelity as something that is expressed in honoring and not abusing the feelings of a partner, in listening well, in speaking honestly and from one's depths, in a willingness to be vulnerable (75-76). Clark's recipe for fidelity - though it may not include sexual exclusivity - is certainly not without rigor. In a litany of moral imperatives, he goes on to insist, "We must also be faithful to our values within our relationships, we must cherish openness and honesty and we must trust one another deeply; we must be committed not only to our individual growth as persons but also to the growth of our relationships themselves" (76).

Further reintepretation of the concept of fidelity might mean honesty between friends as well as between lovers. It might mean consideration for the feelings and the well-being of others. Questions might be raised as to whether we are to be faithful to rules or to persons, to a legal agreement or to a relationship.

As conservatives tend to be literal in their understanding of scripture, they tend to be literal in their adherence to rules. In fact, their lives are given structure by those rules that are understood to reflect God's intentions for humanity. Like the writer of Psalm 19, they see the existence of rules as a sign of God's care for humanity and of God's willingness to provide people with guidance and direction: "The law of the LORD is perfect, / reviving the soul; / the decrees of the LORD are sure, / making wise the simple; / The precepts of the LORD are right, / rejoicing the heart; / the commandment of the LORD is clear, / enlightening the eyes" (Psalm 19:7-8). Good rules, according to this view, are intended to be not a burden but a blessing. They are designed for human benefit.

An ethic of rules, however, tends to eliminate tolerance of diversity. Liberals are more inclined to be relativist (rather than absolutist) when it comes to moral decision-making - more likely to see shades of gray, more apt to see value in situational ethics, more open to the possibility that rules may have their exceptions, more tolerant of differing points of view. Liberals question whether an ethic of rules that sees a bad heterosexual marriage as better than a good homosexual relationship is an ethic that can withstand scrutiny. 
Radicals may take this one step further. Some, seeing an impossibility in doing ethics in an objective way, argue that ethics must be done in the subjective context of individual experience and cultural diversity. This means, for example, that one group cannot do another group's ethics for them (e.g., straights for gays), and that gays themselves cannot borrow any but the most general ethical constructs from other cultures but must develop their own. Although gay men may have a diversity of life experiences and interpret those experiences in a variety of ways, many share an emphasis on an 'ethic of relationship' rather than an 'ethic of rules.' They have found that rules have been used, by and large, to oppress them, and therefore they have to find other expressions of value.

It should be added that a radical argument for the value of a gay element in society is that, historically, queer folk have served the usefully subversive purpose of destabilizing society by providing alternative lifestyles and by asking awkward questions. Conservatives who value stability in society may experience this challenge as an unwelcome threat and feel that society would be better off without it. Liberals, while not actually sharing counterculture values, might still understand them as a useful addition to the societal mix and, within limits, would tolerate them.

\section{Conclusion}

Whether we are consistent in our outlook or not, it should be apparent by this point that the approaches to gay issues which I have characterized as conservative, liberal, and radical each have a certain consistency within themselves.

Those whom I have described as conservative tend to be literal (or at least selectively literal) in their reading of the Bible and in their adherence to biblically inspired rules. They see the subjugation of bodily appetites as one of our spiritual goals. They understand it as God's intention that human beings should be heterosexual and therefore perceive departures from this norm as sinful or unhealthy and as bad choices that may be corrected. The ordination of 'practicing' homosexuals and the blessing of same-sex unions are inconsistent with conservative understanding. In churches that have a conservative ethos, gay men and lesbians are not made to feel accepted as they are.

Liberals, drawing on their heritage of tolerance and a positive 


\section{4 / Saunders}

and progressive view of human nature, bring a degree of ambiguity to the subjects under discussion. Seeing shades of gray, they try to refrain from being judgmental but look for common ground somewhere in the middle. They soften the harsher injunctions of scripture by emphasizing the factor of context. They see sexual orientation as a given and minimize the differences between gay and straight. Nevertheless there is sometimes subtle, sometimes overt heterosexism in many of their expressions of value which implies acceptance of only a limited range of human diversity and a limited range of sexual behaviors. Gay church members - ordained and lay - are accepted with conditions attached.

Radicals celebrate the diversity that liberals merely tolerate. They are disinclined to defend scripture when it seems to them to be indefensible. Their radical critique of what they regard as unhealthy traditions includes a rejection of the body/spirit split and a call for bodyself integration. On some issues, essentialist radicals find themselves lining up with the liberals (on the issue of choice, for instance). But social constructionists - surprisingly perhaps - find themselves agreeing with conservatives on the matter of choice and in emphasizing the things that distinguish gays from straights. Rather than accepting the heterosexism of conservative judgments or of liberal tolerance, they seek a positive ethic developed by gay men for gay men, an ethic that would provide appropriate guidance for gay Christians - clergy and lay - in their intimate relationships.

Is it possible for these three groups to talk to one another? Some despair of the possibility. In fact, many gay Christians say, for example, that they are tired of debating the biblical texts. They have been over that ground too often and find that few people are persuaded to budge from their position - whatever it may be - by the sheer weight of argument. If the pro-choice and pro-life camps on the abortion issue cannot begin to have a conversation because they disagree on such a basic matter as a definition of the moment at which life begins, those who disagree about fundamental aspects of homosexuality may also find chances of a fruitful exchange of views to be rather slim. Nevertheless those who have sought changes in denominational policies on the acceptance of gays and lesbians have had to consider which tactics are most likely to effect such changes.

The dynamics can be interesting. At first sight, radicals and conservatives can look like two solitudes, with liberals attempting to 
bridge the gap. Positive results, however, can be meager. At some denominational gatherings - the worldwide Anglican Communion's Lambeth Conference of 1998 , for example - statements about points on which consensus has been found often have little to say that is substantive and are reduced to vapid platitudes. Some radicals, sensing that conservatives might be more open to a liberal approach than to a radical one, soften their position - and may at times even misrepresent themselves - in order to persuade conservatives that their fears of difference are unfounded. If conservatives could accept the idea that sexual orientation is not chosen and that gays and lesbians want to live a lifestyle that is similar to the one espoused by most straight Christians, it is felt that the road to acceptance may be made easier.

Other radicals have found, however, that they can have a more significant conversation with conservatives if they stick to their beliefs rather than masquerade as liberals. A radical, social constructionist, lesbian member of Affirm United (the United Church's unofficial organization for gay and lesbian members and their supporters) once told me that she found conservatives easier to deal with than liberals because, although they disagreed in their positions, they at least agreed about what was at issue. They agreed, for example, that there was an element of choice in sexual orientation, although what conservatives call a bad choice radicals call good. They agreed that there is a lot more to being gay than the sex of the people one happens to be attracted to, although again what conservatives call bad - lifestyle choices, political agendas, and the rest - radicals call good. By minimizing issues of difference and choice, liberals - much as they might like to find common ground - have a harder time finding it either with conservatives or with radicals because the things conservatives and radicals consider significant liberals regard as relatively unimportant.

The dilemma for conservatives and radicals in particular is whether to see as their goal the transformation of their opponent's viewpoint or simply the clear articulation - and ultimate victory - of their own position. When lines are drawn so firmly, a softening of one's opponent's position may be effected only by a lack of candor about one's own. Frankness about one's own views may simply produce agreement to disagree and a return to battle positions in which the enemy is frequently demonized.

In the United Church, liberals hoped to keep everyone together both before and after 1988. At the General Council of that year, liberals 


\section{$76 /$ Saunders}

even sought a compromise that everyone could live with. In the event, many conservatives in the church saw the General Council's decision to open ordered ministry to self-declared homosexuals as a defeat for them and withdrew their membership; others were loud in their protests but stayed in the church. For radicals, the decision was a step forward. However, for the next decade it was a liberal call for a time of healing that prevailed and, for the most part, kept matters of human sexuality off the church's official agenda. In this atmosphere it was not until the General Council of August, 2000 (the fifth General Council since 1988) that the national church returned to a significant discussion of gay issues. The measures adopted at that meeting dealt a further blow to conservatives in the United Church. ${ }^{17}$ In the debate that preceded decision-making, those liberals who argued for compromise or deferment were overruled. In the end, it was the radicals who gained the most ground.

In 1988 the surface issue was whether or not gay men and lesbians should be ordered ministers. The underlying issue was whether or not gay men and lesbians were welcome in the church as they are. By 2000, the United Church's General Council was ready to address those underlying issues more directly. Specifically, the General Council of that year renounced a statement of the General Council of 1960 in which homosexuality was described as a sin and replaced it with the statement that "lesbian, gay, bisexual and transgendered as well as heterosexual orientations are gifts from God, part of the marvelous diversity of creation" (Beck 2). In renouncing the earlier declaration, the General Council clearly rejected the conservative position. The language of the new resolution - by affirming and celebrating sexual diversity rather than merely tolerating it - comes closer to a radical stance than to a liberal one.

Following the practice already adopted by a number of

\footnotetext{
${ }^{17}$ For purposes of comparison, it is of interest to note the actions of the United Church's sister denominations in the United States. During the same summer in which the United Church of Canada was enacting measures that dealt further blows to the denomination's conservatives, conservative positions were triumphing south of the border. The United Methodist Church (the second largest Protestant denomination in the United States) ruled against the ordination of practicing homosexuals, while the Presbyterian Church (USA) extended a moratorium on the discussion of sexual standards for ordination. Both denominations, along with the Episcopalian (Anglican) Church rejected attempts to legitimize same-sex unions.
} 
congregations, the General Council also decided to "affirm lesbian and gay partnerships" and to "recognize them in church documentation and services of blessing, and actively work for their civil recognition" (Beck 2). This action clearly marked another defeat for conservatives in the church. But was it a victory for the liberals or for the radicals? Liberals might be happier than radicals to see the church sanctioning partnerships that approximate heterosexuals' pairings. But avoidance of the word 'marriage' - though it may have been based on tactical considerations - would meet with the approval of most radicals.

Another measure adopted by the General Council seems to reflect liberal values. Following renunciation of the position that homosexuality is sinful, General Council decided to encourage the various levels of church councils and the church's membership "to learn ways to offer healing for the damage inadvertently caused by the historic stance of our church on homosexuality" (Beck 2). The statement reflects a liberal view of history that minimizes the harm done and takes a relatively benign view of human nature and human failings. Radicals might be less inclined to see the harmful results of institutional homophobia in church and society as inadvertent. Suspecting that harmful motives and actions cannot be easily excused, radicals might be less sanguine than liberals about the ease with which healing may be effected.

In concentrating on General Council's decisions, it is possible to overlook the long and lively debate that led to them. A variety of points of view can still be articulated clearly in the courts of the church. It may also be possible to forget that, on matters of sexuality at least, General Council has a history of moving more quickly than the general membership. Perhaps what the majority of church members have found to be acceptable is a liberal version of gay realities. At the grass-roots level, the radical perspective of those realities is a long way from general acceptance.

\section{Works Cited}

Archer, Bert. The End of Gay. Toronto: Doubleday, 1999.

Beck, Marney. "Controversial Resolutions on Sexuality Approved." 37th General Council News 37.8 (19 Aug. 2000): 2-3.

Boston Women's Health Book Collective. Our Bodies, Our Selves. 
New York: Simon, 1984.

Clark, J. Michael. Defying the Darkness: Gay Theology in the Shadows. Cleveland, OH: Pilgrim, 1997.

Comstock, Gary David. Gay Theology without Apology. Cleveland, OH: Pilgrim,1993.

Countryman, L. William. Dirt, Greed, and Sex. Philadelphia: Fortress, 1988.

The Diagram Group. Man's Body: An Owner's Manual. New York:

Paddington, 1976.

Faris, Donald L. The Homosexual Challenge. Markham, ON: Faith Today, 1993.

Ferry, James. In the Courts of the Lord: A Gay Minister's Story. Toronto: Key Porter, 1993.

Fiorenza, Elizabeth Scheussler. Bread not Stone: The Challenge of Feminist Biblical Interpretation. Boston: Beacon, 1984.

Goss, Robert. Jesus Acted Up: A Gay and Lesbian Manifesto. San Francisco: Harper, 1994.

Harris, Daniel. The Rise and Fall of Gay Culture. New York: Hyperion, 1997.

Helminiak, Daniel A. What the Bible Really Says about Homosexuality. San Francisco: Alamo Square, 1994.

Heyward, Carter. Touching our Strength: The Erotic as Power and the Love of God. San Francisco: Harper, 1989.

Kaiser, Charles. The Gay Metropolis 1940-1996. Boston: Houghton, 1997.

Kennedy, James. "Gays Need Equality, But Not Marriage." Edmonton Journal 27 June 1999: A15.

Long, Ronald E. "An Affair of Men: Masculinity and the Dynamics of Gay Sex." Journal of Men's Studies 3 (1994): 21-48.

Millward, Ted. What the Bible Says to Homosexuals. Winnipeg: Council on Homosexuality and Religion, 1981.

Nelson, James B. Body Theology. Louisville, KY: Westminster/Knox, 1992.

Spong, John S. Address to the Diversity Conferences of Alberta Society, Knox-Metropolitan United Church, Edmonton, Alberta, May 3, 1999.

Stein, Edward, ed. Forms of Desire: Sexual Orientation and the Social Constructionist Controversy. New York: Garland, 1990.

United Church of Canada.. Gift, Dilemma, and Promise: A Report 
Conservative, Liberal, Radical / 79

and Affirmations on Human Sexuality. Toronto: United Church of Canada General Council, 1984.

White, Edmund. States of Desire: Travels in Gay America. New York: Dutton, 1980.

Wushke, Ralph. Address to the Second Diversity Conference, Edmonton, Alberta, April 9, 2000.

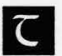

